\title{
De novo transcriptome analysis reveals insights into dynamic homeostasis regulation of somatic embryogenesis in upland cotton (G. hirsutum L.)
}

\author{
Wen-Han Cheng ${ }^{1} \cdot$ Hua-Guo Zhu ${ }^{1} \cdot$ Wen-Gang Tian ${ }^{1} \cdot$ Shou-Hong Zhu ${ }^{1} \cdot$ \\ Xian-Peng Xiong ${ }^{1} \cdot$ Yu-Qiang Sun ${ }^{1,2} \cdot$ Qian-Hao Zhu $^{3} \cdot$ Jie Sun $^{1}$
}

Received: 28 March 2016 / Accepted: 7 July 2016 / Published online: 10 August 2016

(C) The Author(s) 2016. This article is published with open access at Springerlink.com

\begin{abstract}
Plant regeneration via somatic embryogenesis (SE) is the key step for genetic improvement of cotton (Gossypium hirsutum $\mathrm{L}$.) through genetic engineering mediated by Agrobacteria, but the molecular mechanisms underlying SE in cotton is still unclear. Here, RNA-Sequencing was used to analyze the genes expressed during SE and their expression dynamics using RNAs isolated from nonembryogenic callus (NEC), embryogenic callus (EC) and somatic embryos (SEs). A total of 101, 670 unigenes were de novo assembled. The genes differentially expressed (DEGs) amongst NEC, EC and SEs were identified, annotated and classified. More DEGs were found between SEs
\end{abstract}

Wen-Han Cheng and Hua-Guo Zhu are co first authors and they have contributed equally in this study.

Electronic supplementary material The online version of this article (doi:10.1007/s11103-016-0511-6) contains supplementary material, which is available to authorized users.

Jie Sun

sunjie@shzu.edu.cn

Wen-Han Cheng

kaven_53@163.com

Hua-Guo Zhu

zhgroger@sohu.com

1 The Key Laboratory of Oasis Eco-Agriculture, College of Agriculture, Shihezi University, Shihezi 832000, Xinjiang, China

2 Key Laboratory of Plant Secondary Metabolism and Regulation of Zhejiang Province, College of Life Sciences, Zhejiang Sci-Tech University, Hangzhou 310018, Zhejiang, China

3 CSIRO Agriculture Flagship, GPO Box 1600, Canberra 2601, Australia and EC than between EC and NEC. A significant number of DEGs were related to hormone homeostasis, stress and ROS responses, and metabolism of polyamines. To confirm the expression dynamics of selected DEGs involved in various pathways, experiments were set up to investigate the effects of hormones (Indole-3-butytric acid, IBA; Kinetin, $\mathrm{KT}$ ), polyamines, $\mathrm{H}_{2} \mathrm{O}_{2}$ and stresses on SE. Our results showed that exogenous application of IBA and KT positively regulated the development of EC and SEs, and that polyamines and $\mathrm{H}_{2} \mathrm{O}_{2}$ promoted the conversion of $\mathrm{EC}$ into SEs. Furthermore, we found that low and moderate stress is beneficial for proliferation of EC and SEs formation. Together, our global analysis of transcriptomic dynamics reveals that hormone homeostasis, polyamines, and stress response synergistically regulating SE in cotton.

Keywords Gossypium hirsutum L. · Transcriptome · Somatic embryogenesis (SE) - Indole-3-butytric acid · Kinetin $\cdot$ Polyamines $\cdot$ Stress-response

\section{Introduction}

Crop losses due to multiple stresses have been predicted to be much greater than previously estimated in the coming future, especially due to climate change and industry development (Chen et al. 2015). Genetic improvement through breeding is the most efficient strategy for enhancing crop's stress tolerance. In addition to traditional breeding approaches, genetic transformation provides an alternative method to improve pest and disease resistance, as well as yield, of crops (Markram et al. 1997; Wu et al. 2008). For the majority of crops, Agrobacterium-mediated transformation is the method of choice for genetic modification. The prerequisite of this method is to have a highly efficient and 
repeatable system for tissue culture and plant regeneration via somatic embryogenesis (SE) or organogenesis.

Many studies have investigated physiological and biochemical changes during SE in various plant species with a focus on understanding the mechanisms of gene regulation related to SE. These efforts identified genes differentially expressed in somatic embryos (SEs), highlighted the pathways likely to be involved in SE and discovered molecular or protein markers for SE (Mantiri et al. 2008). Some of the identified genes have been experimentally demonstrated to play an important role in SE. For instance, Arabidopsis thaliana plants transformed with the SOMATIC EMBRYOGENESIS RECEPTOR-LIKE KINASE 1(AtSERK1) gene showed a marked increase in SE compared to wild-type cultures (Hecht et al. 2001). In Arabidopsis, transcription factors $L E A F Y$ COTYLEDON 1 ( $L E C 1)$ is required for embryo development and $L E C 2$ induces somatic embryo development in vegetative cells. Ectopic expression of $L E C 1$ (Lotan et al. 1998) or LEC2 (Stone et al. 2001) caused spontaneous formation of SEs on intact plants or explants. AGL15 is another transcription factor that promotes SE in Arabidopsis (Harding et al. 2003). The BABY BOOM (BBM) gene can promote SEs in transgenic Arabidopsis and Brassica when ectopically overexpressed (Boutilier et al. 2002). Medicago truncatula SOMATIC EMBRYO RELATED FACTOR1 (MtSERF1) is essential for somatic embryo development and is induced by ethylene (Mantiri et al. 2008).

Cotton is one of the most important economic crops in the world, providing excellent natural fiber, and is also a source of oil. Cotton plantlets can be regenerated via SE using various combinations of plant growth-regulators, such as 2,4-Dichlorophenoxyacetic acid (2,4-D), indole-3-butyric acid (IBA), and naphthalene acetic acid (NAA) in combination with Kinetin (KT) (Sun et al. 2006). But cotton remains to be one of the notoriously recalcitrant plant species for plant regeneration via SE. So far, only few genotypes have been successfully used in gene transformation and genetic engineering. SE in cotton usually requires a very long culture time, and has a high frequency of abnormal embryos. To understand the molecular mechanisms underlying cotton SE and identify genes and critical pathways for cotton SE, suppression subtractive hybridization, macroarray and transcriptome during SE has been recently investigated (Xu et al. 2013; Yang et al. 2012; Zeng et al. 2006). Global transcriptome analyses suggested that auxin and cytokinin signaling pathways are critical in dedifferentiation of somatic cells and redifferentiation of SEs in cotton. In addition, stress-responsive genes and pathways were also found to be involved in SE (Yang et al. 2012). A more recent study has shown that the function of GhCKI (CASEIN KINASE I), a unique key regulatory factor strongly affecting cotton $\mathrm{SE}$, is achieved by regulating auxin homeostasis through the network including other three genes, i.e. GhLEC1, GhTCP15
(TEOSINTE BRANCHED1-CYCLOIDEA-PCF15) and GhPIF4 (PHYTOCHOME INTERACTING FACTOR4) (Min et al. 2015). Despite these reports, we still know little about the molecular mechanisms underlying cotton SE.

In this study, we used Xinluzao 33 (Gossypium hirsutum L.), one of the main cotton cultivars planted in Xinjiang Province, China, to investigate the transcriptome profiles of tissues from different stages during SE. Plant regeneration via SE using Xinluzao 33 is problematic because of the long time required for embryogenic callus (EC) induction and the low ratio of somatic embryo differentiation. Our transcriptome studies not only confirmed the importance of auxin and cytokinin homeostasis in cotton SE, but revealed the importance of genes involved in the polyamine metabolic pathway and stress response in cotton SE. Our results provided foundation and clues for establishing a reproducible and highly efficient plant regeneration system that can be used in a diverse of cotton genotypes for fast and precise genetic improvement by genetic engineering.

\section{Materials and methods}

\section{Plant materials and culture conditions}

The method for cotton cultivar Xinluzao 33 SE used in this study has been previously described (Cheng et al. 2015; Sun et al. 2006). Non-embryogenic callus (NEC) (45 days), EC and SEs (a mixture of globular embryos, torpedo embryos and cotyledon embryos; SEs) (Supplementary Fig. 1) were sampled for RNA-Sequencing (RNA-seq), determinating the level of hormones, polyamines, $\mathrm{H}_{2} \mathrm{O}_{2}$, and qRT-PCR.

\section{RNA extraction, library construction, and RNA-Sequencing}

The RNA library construction, and RNA-Sequencing was performed by Illumina Genome Analyzer IIx at Beijing Genomics Institute (BGI)-Shenzhen, China. The NEC, EC and SEs samples were biologically replicated once, i.e. in total six libraries were used in RNA-Seq.

\section{Analysis of sequencing data and identification of differentially expressed genes}

The trimmed and filtered of raw reads and identification of differentially expressed genes in databases were based on a previous published paper (Xiang et al. 2010). Annotation of the differentially expressed unigenes was based on the Gossypium raimondii genome and $A$. thaliala genome (Kaul et al. 2000; Mayer et al. 1999; Wang et al. 2012). The genes mentioned in this study were also BLAST in other two recently reported $G$. hirsutum genome (TM-1) databases ( $\mathrm{Li}$ 
et al. 2015; Zhang et al. 2015), in order to confirm the gene sequences and ID.

\section{Establishment of suspension cultures of uniform embryogenic callus}

Suspension culture of uniform EC that was used in various physiological experiments outlined below was established following our previously described method (Cheng et al. 2015).

\section{Exogenous treatments of polyamines, $\mathrm{H}_{2} \mathrm{O}_{2}$, IBA, KT and simulated stresses}

To determine the effects of polyamines, IBA (Indole-3-butytric acid) and KT on the conversion of EC into SEs, $60 \mu \mathrm{L}$ of uniform embryogenic calli was cultured on somatic embryo induction medium supplemented with $1 \mathrm{mM}$ of putrecine (Put), $1 \mathrm{mM} \mathrm{H} \mathrm{H}_{2}$, or $0.15 \mathrm{mg} / \mathrm{L} \mathrm{IBA}+0.15 \mathrm{mg} / \mathrm{L} \mathrm{KT}$. All reagents were purchased from Sigma Chemical Co. (St. Louis, $\mathrm{MO})$. The simulated stress was performed with Phytagel (2.5, $4 \mathrm{~g} / \mathrm{L})$ or $\mathrm{NaCl}(0,25,50,100 \mathrm{mM})$ in the MS medium. Each treatment was repeated three times biologically.

\section{Determination of polyamine concentration}

Polyamine (PA) concentrations were determined using the high performance liquid chromatography (HPLC) method following the procedure previously described (Cheng et al. 2015). The assays were biologically repeated three times.

\section{Detection of hydrogen peroxide by 3 , 3'-diaminobenzidine (DAB)}

Detection of hydrogen peroxide by 3, 3'-diaminobenzidine (DAB) staining in each sample was achieved using our previously described method (Cheng et al. 2015). The assays were biologically repeated three times.

\section{Determination of IAA, KT, GA and ABA}

IAA, KT, GA and ABA were determined using an ELISA Assay Kit and corresponding antibodies produced by the Jiancheng Biochemistry Company (Nanjing, China) according to the manufacturer's instructions. The assays were biologically repeated three times.

\section{RNA extraction and quantitative real time PCR (qRT-PCR)}

RNA extraction, qRT-PCR and expression assay methods were described in our previous paper (Cheng et al. 2015). The means of the three biological experiments were calculated as the expression level of the genes analyzed. Primers used in qRT-PCR are listed in Supplementary Table 1.

\section{Statistical analysis}

Analysis of variance was performed using the SPSS16.0 statistical analysis package. Differences between means were compared by Fisher's least-significant-difference test at the 5 and $1 \%$ probability levels.

\section{Results}

\section{RNA-sequencing and transcriptome de novo assembly}

Generally, the process of cotton SE includes NEC induction, EC induction, differentiation of SEs, and plant regeneration (Supplementary Fig. 1). To investigate the transcriptome dynamics during cotton SE, we performed RNA-Seq using mRNA extracted from NEC, EC and SEs.

In total, 168,196,388 75-bp paired-end raw reads were generated. For all three samples, the percentage of nucleotides with a quality score above 20 (Q20) was over $98.00 \%$, the percentage of reads containing $\mathrm{N}$ was lower than $0.02 \%$ and the GC percentage was $\sim 4 \%$ (Supplementary Table 2). After filtering, 160,407,732 clean reads were retained and used in transcriptome de novo assembly using the Trinity program. As a result, 97,857, 87,997 and 84,176 unigenes were assembled in NEC, EC and SEs, respectively (Supplementary Table 3). Combining unigenes from all three samples, in total, 101,669 non-redundant unigenes were assembled. The majority of unigenes were $200-500 \mathrm{bp}$ in length, and the numbers of unigenes and contigs decreased with the increase of the unigene length (Supplementary Table 3).

\section{Functional annotation of unigenes}

Unigenes were functionally annotated by searching against the NT, Swiss-Prot, KEGG, COG and GO databases using the Blast2GO algorithm with an $\mathrm{E}$ value $\leq 10^{-5}$. Of the total 101,669 non-redundant unigenes, 61,389, 43,333, 39,721, 25,923 and 50,884 had a hit in the NR, NT, Swiss-Prot, KEGG, COG and GO database, respectively. The predicted amino acid sequences of the unigenes were further aligned against the Pfam database (E value $\leq 10^{-6}$ ) using the HMMER software. Altogether, 74,306 (73\%) unigenes had an annotated function. According to the COG (http://www. ncbi.nlm.nih.gov/COG) functional classification, the unigenes assembled were categorized into 25 groups, and were mostly covered by the inherent function, such as RNA processing, transcription, replication, recombination, repair and nucleotide or amino acid metabolism (Fig. 1a). Some unigenes were annotated to be involved in signal transduction, 
(A)

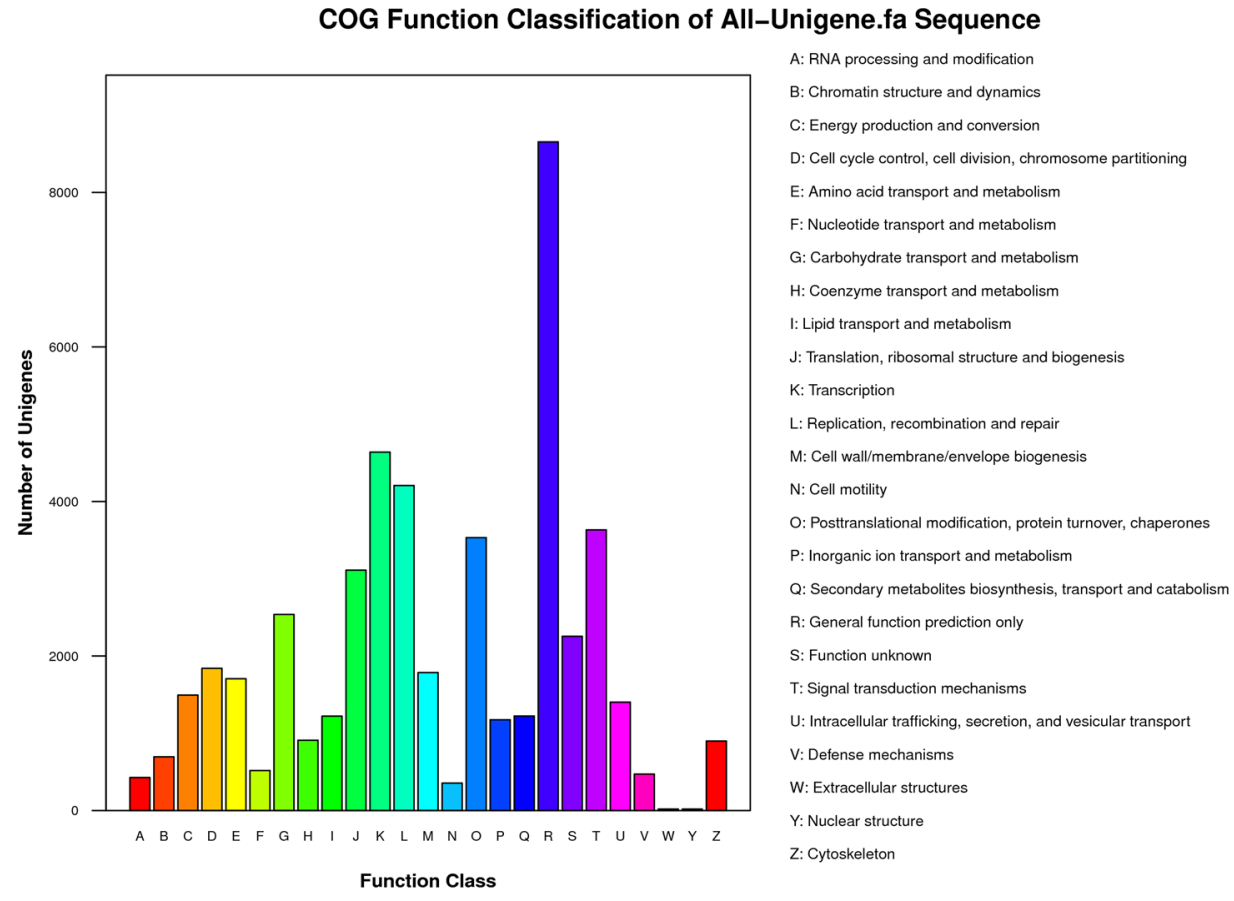

(B)

NEC-vs-EC

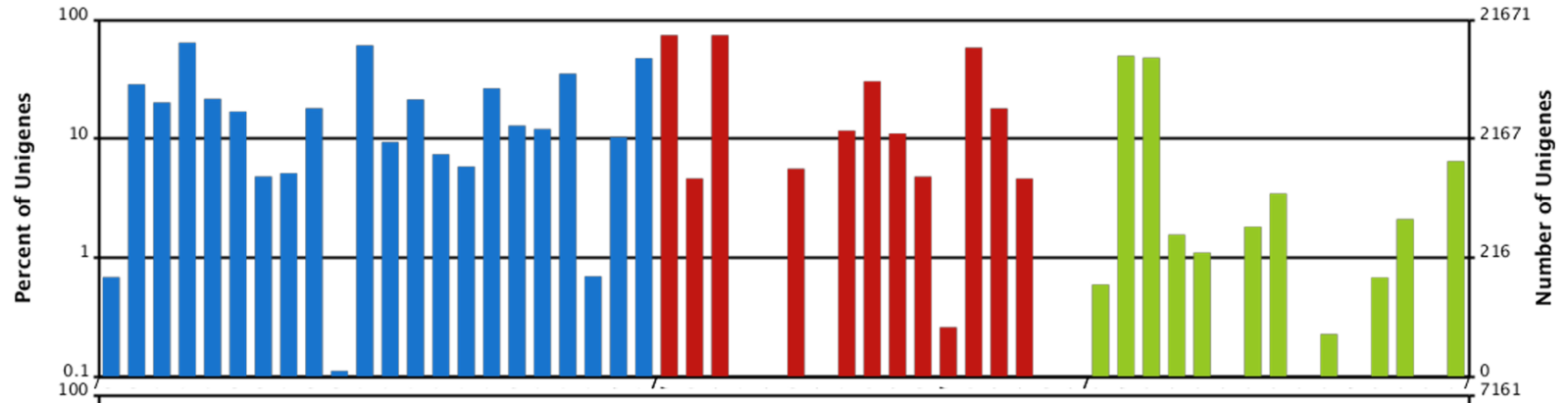

(C)

EC-vs-SEs
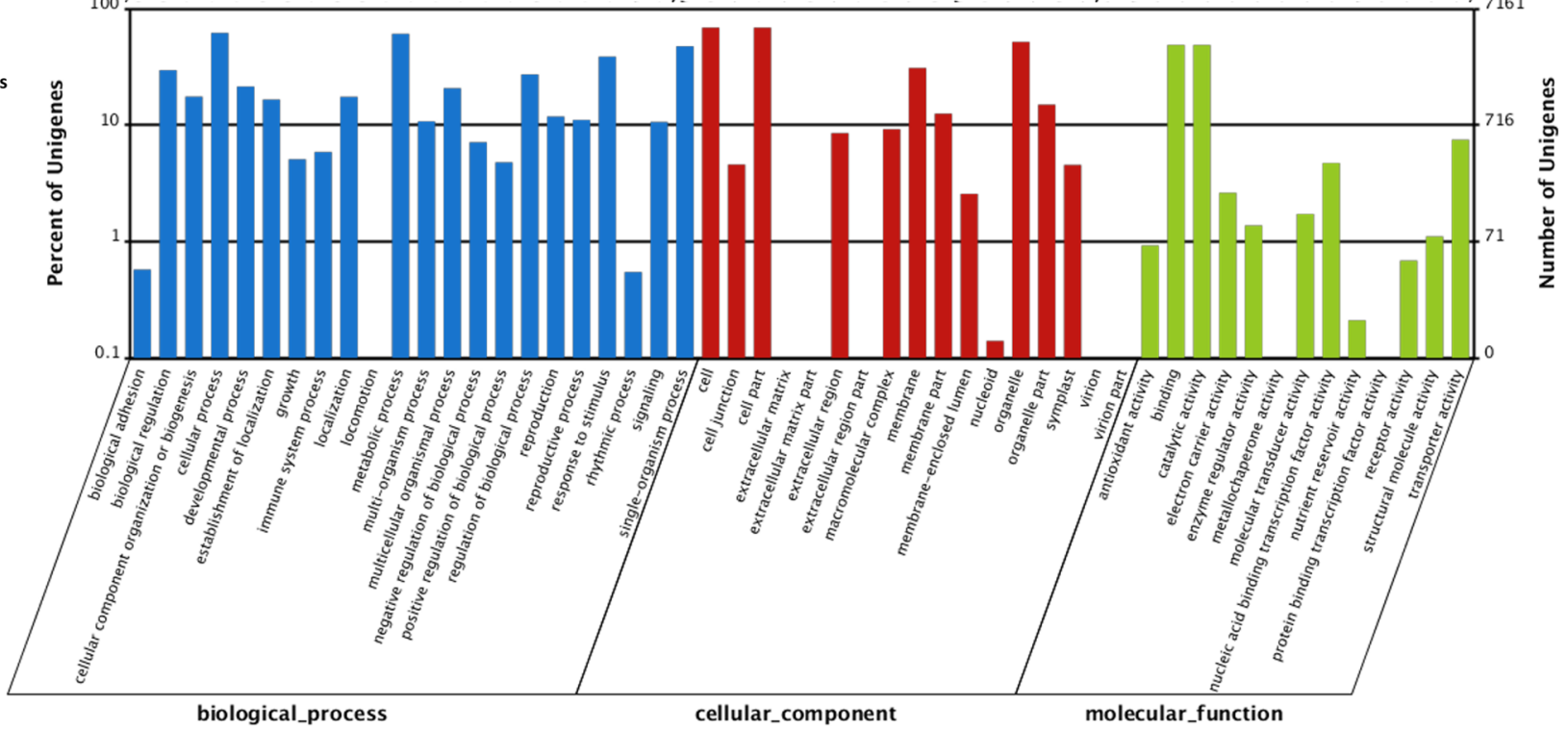

Fig. 1 Function classification of all unigenes in COG and GO. a COG function classification. $\mathbf{b}$ GO classification of unigenes in embryogenic callus compared with non-embryogenic callus at three levels. c GO classification of unigenes in somatic embryos compared with embryogenic callus at three levels 
cell cycle control and cell division. Genes related to plant growth, developmental progress and responses to stimuli were also well covered by the de novo assembly (Fig. 1a).

Based on GO (http://www.geneontology.org) classification, the majority of the unigenes under cellular component were involved in cell, cell part, organelle, membrane, organelle part, macromolecular complex, membrane part, cell junction and extracellular region. Molecular function categories were mostly clustered in binding, catalytic activity and transporter activity. The annotated unigenes clustered under biological process mainly involved in cellular process, metabolic process, single-organism process, response to stimulus and regulation of biological process. Comparing EC with SEs, there were more unigenes involved in locomotion at biological process level, more unigenes involved in macromolecular complex and nucleoid at cellular component level, and more unigenes involved in structural molecule activity at molecular function level (Fig. 1b, c).

\section{Comparative analysis of differentially expressed unigenes in NEC, EC and SEs}

Growth of NEC is in the process of dedifferentiation of vegetative growth, while formation of EC and development of SEs are regarded as in the process of dedifferentiation of reproductive growth. Spatial analysis was also performed on differentially expressed unigenes to ascertain the degree of overlap existing between the three different developmental processes during cotton SE. There were 94,020, 84,001 and 86,358 differentially expressed unigenes in NEC, EC and SEs (Fig. 2a). Among these, more than half (75.7\%) of the differentially expressed genes were present in all three developmental processes. Significant numbers of genes were present in one developmental process only: 13,505 unigenes were only differentially expressed in NEC, 786 differentially expressed unigenes were only switched on/off EC, and 545 genes changed their expression level in SEs, which suggested that distinct spatial transcriptional profiles were present (Fig. 2a). Compared with NEC, EC had 5905 and 5983 unigenes down- and up-regulated, respectively. Compared with EC, SEs had 23,172 down-regulated unigenes and 19,361 up-regulated unigenes (Fig. 2b). These results suggest that the cotton transcriptome undergoes significantly dynamic changes during SE, particularly during the period from EC to SEs.

\section{Pathways of differentially expressed unigenes based on KEGG}

In total, there were 101,669 differentially expressed unigenes amongst NEC, EC and SEs, which were mainly involved in 127 pathways based on KEGG annotation. The pathways related to metabolites (e.g.purine, glycerophospholipid, starch and sucrose, ether lipid, amino sugar, nucleotide sugar, pyruvate) and biosynthesis of secondary metabolites (e.g. phenylpropanoid, stilbenoid, diarylheptanoid, gingerol and flavonoid), covered almost half of the differentially expressed unigenes. A considerable number of unigenes involved in DNA repair and replication, transcription, mRNA translation and protein folding, sorting and degradation were differentially regulated during the development of EC and SEs. Additionally, some stimulus pathways (e.g. plant hormone signal transduction and plant-pathogen interaction), ubiquitin mediated proteolysis, oxidative phosphorylation, $\mathrm{ABC}$ transporters and circadian rhythm were also found to be covered by differentially expressed unigenes. The top 30 pathways with the most number of differentially expressed unigenes are shown in Table 1.
(A)

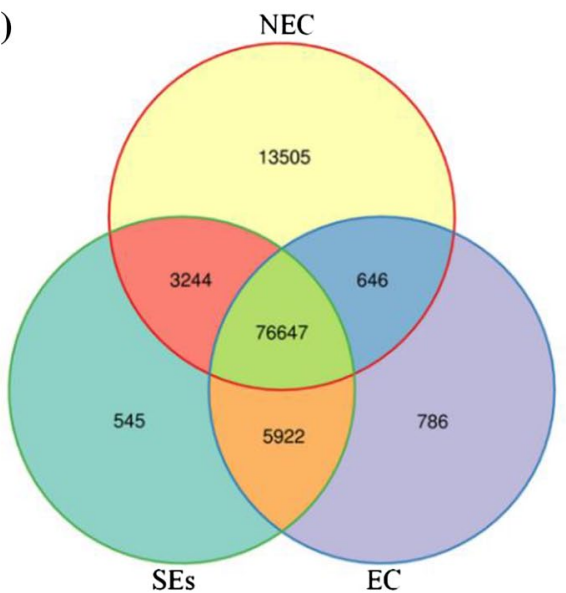

(B)

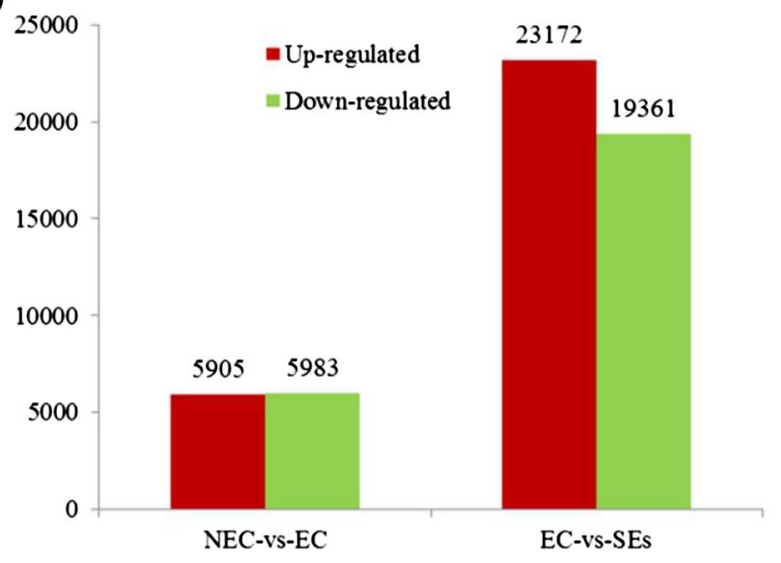

Fig. 2 Statistical analysis of differentially expressed unigenes in NEC, EC and SEs. a The venn diagram of the unigenes in NEC, EC and SEs. b Statistical analysis of up/down regulated unigenes in NEC vs EC and EC vs SEs 
Table 1 Pathways of differentially expressed unigenes annotated in KEGG

\begin{tabular}{|c|c|c|c|c|c|c|c|}
\hline No. & Pathway annotated in KEGG & $\begin{array}{l}\text { Differentially } \\
\text { expressed unigenes } \\
\text { with pathway anno- } \\
\text { tation }(101,669)\end{array}$ & $\mathrm{P}$ value & $\mathrm{Q}$ value & $\begin{array}{l}\text { Pathway } \\
\text { ID }\end{array}$ & Level 1 & Level 2 \\
\hline 1 & Metabolic pathways & $3772(20.81 \%)$ & 0.000294816 & $1.70 \mathrm{E}-03$ & ko01100 & Metabolism & Global map \\
\hline 2 & $\begin{array}{l}\text { Biosynthesis of secondary } \\
\text { metabolites }\end{array}$ & $1858(10.25 \%)$ & $7.63 \mathrm{E}-08$ & $1.21 \mathrm{E}-06$ & ko01110 & Metabolism & Global map \\
\hline 3 & $\begin{array}{l}\text { Plant hormone signal } \\
\text { transduction }\end{array}$ & $1098(6.06 \%)$ & 0.002668437 & $1.21 \mathrm{E}-02$ & ko04075 & $\begin{array}{l}\text { Environmental } \\
\text { information } \\
\text { processing }\end{array}$ & Signal transduction \\
\hline 4 & Plant-pathogen interaction & $1090(6.01 \%)$ & 0.01333107 & $5.29 \mathrm{E}-02$ & ko04626 & $\begin{array}{l}\text { Organismal } \\
\text { systems }\end{array}$ & $\begin{array}{l}\text { Environmental } \\
\text { adaptation }\end{array}$ \\
\hline 5 & RNA transport & $1063(5.86 \%)$ & 0.02651119 & $8.63 \mathrm{E}-02$ & ko03013 & $\begin{array}{l}\text { Genetic informa- } \\
\text { tion processing }\end{array}$ & Translation \\
\hline 6 & Spliceosome & $735(4.05 \%)$ & 0.05205961 & $1.54 \mathrm{E}-01$ & ko03040 & $\begin{array}{l}\text { Genetic informa- } \\
\text { tion processing }\end{array}$ & Transcription \\
\hline 7 & $\begin{array}{l}\text { Ribosome biogenesis in } \\
\text { eukaryotes }\end{array}$ & $655(3.61 \%)$ & 0.949479 & $1.00 \mathrm{E}+00$ & ko03008 & $\begin{array}{l}\text { Genetic informa- } \\
\text { tion processing }\end{array}$ & Translation \\
\hline 8 & RNA degradation & $618(3.41 \%)$ & 0.9999995 & $1.00 \mathrm{E}+00$ & ko03018 & $\begin{array}{l}\text { Genetic informa- } \\
\text { tion processing }\end{array}$ & $\begin{array}{l}\text { Folding, sorting and } \\
\text { degradation }\end{array}$ \\
\hline 9 & $\begin{array}{l}\text { Protein processing in endo- } \\
\text { plasmic reticulum }\end{array}$ & $519(2.86 \%)$ & 0.999999 & $1.00 \mathrm{E}+00$ & ko04141 & $\begin{array}{l}\text { Genetic informa- } \\
\text { tion processing }\end{array}$ & $\begin{array}{l}\text { Folding, sorting and } \\
\text { degradation }\end{array}$ \\
\hline 10 & Purine metabolism & $457(2.52 \%)$ & 0.3051416 & $5.96 \mathrm{E}-01$ & ko00230 & Metabolism & Nucleotide metabolism \\
\hline 11 & $\begin{array}{l}\text { Glycerophospholipid } \\
\text { metabolism }\end{array}$ & $422(2.33 \%)$ & 0.5176856 & $8.32 \mathrm{E}-01$ & ko00564 & Metabolism & Lipid metabolism \\
\hline 12 & Pyrimidine metabolism & $418(2.31 \%)$ & 0.6995854 & $1.00 \mathrm{E}+00$ & ko00240 & Metabolism & $\begin{array}{l}\text { Nucleotide } \\
\text { metabolism }\end{array}$ \\
\hline 13 & Endocytosis & $405(2.23 \%)$ & 0.9955326 & $1.00 \mathrm{E}+00$ & ko04144 & Cellular Processes & $\begin{array}{l}\text { Transport and } \\
\text { catabolism }\end{array}$ \\
\hline 14 & Ubiquitin mediated proteolysis & $347(1.91 \%)$ & 0.9976985 & $1.00 \mathrm{E}+00$ & ko04120 & $\begin{array}{l}\text { Genetic informa- } \\
\text { tion processing }\end{array}$ & $\begin{array}{l}\text { Folding, sorting and } \\
\text { degradation }\end{array}$ \\
\hline 15 & Ribosome & $344(1.9 \%)$ & 1 & $1.00 \mathrm{E}+00$ & ko03010 & $\begin{array}{l}\text { Genetic informa- } \\
\text { tion processing }\end{array}$ & Translation \\
\hline 16 & Starch and sucrose metabolism & $333(1.84 \%)$ & 0.1683237 & $3.96 \mathrm{E}-01$ & ko00500 & Metabolism & $\begin{array}{c}\text { Carbohydrate } \\
\text { metabolism }\end{array}$ \\
\hline 17 & Ether lipid metabolism & $256(1.41 \%)$ & 0.1162658 & $3.08 \mathrm{E}-01$ & ko00565 & Metabolism & Lipid metabolism \\
\hline 18 & RNA polymerase & $237(1.31 \%)$ & 0.8641065 & $1.00 \mathrm{E}+00$ & ko03020 & $\begin{array}{l}\text { Genetic informa- } \\
\text { tion processing }\end{array}$ & Transcription \\
\hline 19 & Oxidative phosphorylation & $228(1.26 \%)$ & 0.8898479 & $1.00 \mathrm{E}+00$ & ko00190 & Metabolism & Energy metabolism \\
\hline 20 & Phagosome & $219(1.21 \%)$ & 0.6801155 & $1.00 \mathrm{E}+00$ & ko04145 & Cellular processes & $\begin{array}{l}\text { Transport and } \\
\text { catabolism }\end{array}$ \\
\hline 21 & Phenylpropanoid biosynthesis & $235(1.3 \%)$ & $2.96 \mathrm{E}-09$ & $7.62 \mathrm{E}-08$ & ko00940 & Metabolism & $\begin{array}{l}\text { Biosynthesis of other } \\
\text { secondary metabolites }\end{array}$ \\
\hline 22 & Glycolysis/gluconeogenesis & $233(1.29 \%)$ & $2.46 \mathrm{E}-05$ & $1.74 \mathrm{E}-04$ & ko00010 & Metabolism & $\begin{array}{c}\text { Carbohydrate } \\
\text { metabolism }\end{array}$ \\
\hline 23 & Homologous recombination & $199(1.1 \%)$ & 0.000677679 & $3.59 \mathrm{E}-03$ & ko03440 & $\begin{array}{l}\text { Genetic informa- } \\
\text { tion processing }\end{array}$ & Replication and repair \\
\hline 24 & $\begin{array}{l}\text { Amino sugar and nucleotide } \\
\text { sugar metabolism }\end{array}$ & $196(1.08 \%)$ & 0.8993965 & $1.00 \mathrm{E}+00$ & ko00520 & Metabolism & $\begin{array}{r}\text { Carbohydrate } \\
\text { metabolism }\end{array}$ \\
\hline 25 & $\mathrm{ABC}$ transporters & $186(1.03 \%)$ & 0.842251 & $1.00 \mathrm{E}+00$ & ko02010 & $\begin{array}{l}\text { Environmental } \\
\text { information } \\
\text { processing }\end{array}$ & Membrane transport \\
\hline 26 & Circadian rhythm-plant & $185(1.02 \%)$ & 0.8448579 & $1.00 \mathrm{E}+00$ & ko04712 & $\begin{array}{l}\text { Organismal } \\
\text { systems }\end{array}$ & $\begin{array}{l}\text { Environmental } \\
\text { adaptation }\end{array}$ \\
\hline 27 & Pyruvate metabolism & $184(1.01 \%)$ & 0.4801359 & $8.11 \mathrm{E}-01$ & ko00620 & Metabolism & $\begin{array}{r}\text { Carbohydrate } \\
\text { metabolism }\end{array}$ \\
\hline
\end{tabular}


Table 1 (continued)

\begin{tabular}{|c|c|c|c|c|c|c|c|}
\hline No. & Pathway annotated in KEGG & $\begin{array}{l}\text { Differentially } \\
\text { expressed unigenes } \\
\text { with pathway anno- } \\
\text { tation }(101,669)\end{array}$ & $P$ value & $Q$ value & $\begin{array}{l}\text { Pathway } \\
\text { ID }\end{array}$ & Level 1 & Level 2 \\
\hline 28 & Flavonoid biosynthesis & $176(0.97 \%)$ & $1.46 \mathrm{E}-05$ & $1.32 \mathrm{E}-04$ & ko00941 & Metabolism & $\begin{array}{l}\text { Biosynthesis of } \\
\text { other secondary } \\
\text { metabolites }\end{array}$ \\
\hline 29 & $\begin{array}{l}\text { Arginine and proline } \\
\text { metabolism }\end{array}$ & $140(0.77 \%)$ & 0.002212563 & $1.04 \mathrm{E}-02$ & ko00330 & Metabolism & $\begin{array}{l}\text { Amino acid } \\
\text { metabolism }\end{array}$ \\
\hline 30 & Fatty acid biosynthesis & $67(0.37 \%)$ & 0.3003386 & $5.96 \mathrm{E}-01$ & ko00061 & Metabolism & Lipid metabolism \\
\hline
\end{tabular}

\section{Transcription factors (TFs) involved in cotton SE}

We identified 302 and 112 differentially expressed TFs in EC (EC vs NEC) and SEs (SEs vs EC), respectively. Among these TFs, members of the following families were overrepresented: AP2/EREBP, C3H/C2H2/C2C2-Dof zinc finger proteins, MYB domain-containing proteins, and WRKY domain transcription factors (Fig. 3 and Supplementary Table 4). In addition, some TFs, such as SERK, LEC, WUS, $B B M$, $C K I$ and $A G L 15$, have been previously demonstrated to play a role in SE were also found to be differentially expressed during cotton SE (Fig. 3; Table 2). These TFs are multifunctional regulators in both zygotic and SE with a role in hormone signaling and stress responses (MahdaviDarvari et al. 2015). Some of these TFs have been used as markers of totipotency in plant species. These results suggest that dynamic changes of the expression levels of plant transcription factors are critical for differential and development of EC and SEs.

\section{Auxin and cytokinin played an important role in the transition from NEC to EC and from EC to SEs}

A number of genes involved in auxin and cytokinin synthesis and signal transduction pathways were differentially expressed from NEC to EC and from EC to SEs (Fig. 3; Table 2). For example, from NEC to SEs, the expression levels of $A A O 1-2$ and $C Y P 71 A 13$, genes involved in IAA biosynthesis, were first down-regulated in $\mathrm{EC}$ and then slightly up-regulated in SEs. The gene encoding myrosinase, an IAA biosynthesis related enzyme, was continuously down-regulated from NEC to SEs (Fig. 3). For $A U X 1$, $A U X / I A A$ and $A R F$, genes involved in auxin signal transduction, the highest expression levels were observed in
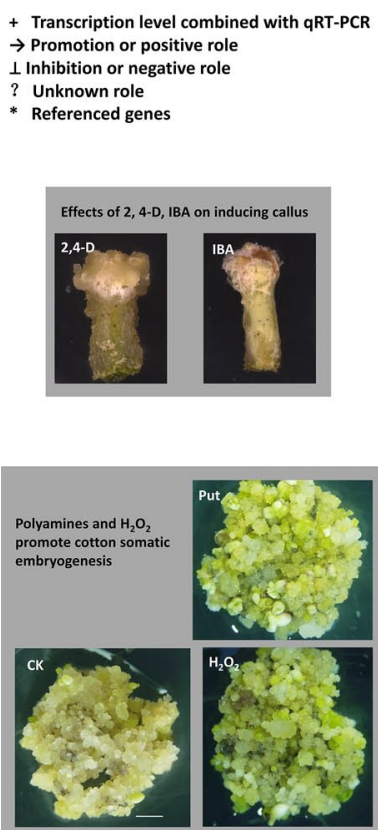

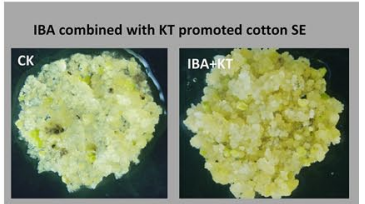
$\mathrm{KT}(\rightarrow), \mathrm{GA}(\rightarrow), \mathrm{ABA}(\rightarrow), \mathrm{ETH}(\perp)$ $\mathrm{JA}(\rightarrow), \mathrm{SA}(\perp)$
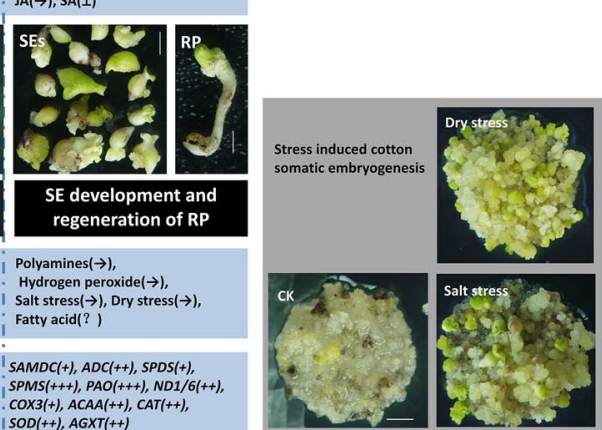

Fig. 3 Differentially expressed TFs, PGRs, stress response related genes during cotton SE and the effects of PGRs, polyamines, $\mathrm{H}_{2} \mathrm{O}_{2}$ and stresses on cotton SE 
Table 2 Differentially expressed unigenes showing SE-specific expression

\begin{tabular}{|c|c|c|c|c|}
\hline \multirow[t]{2}{*}{ Gene ID } & \multirow[t]{2}{*}{ Gene name } & \multirow[t]{2}{*}{ Annotation in KEGG } & \multicolumn{2}{|c|}{ Log2 fold change } \\
\hline & & & NEC vs EC & $\begin{array}{l}\text { SEs } \\
\text { vs EC }\end{array}$ \\
\hline CL11109.Contig1_All & $A D C$ & Polyamines & 1.2 & -1 \\
\hline CL1916.Contig4_All & $S P D S$ & Polyamines & 3.6 & -2.3 \\
\hline CL1916.Contig5_All & $S P M S$ & Polyamines & 4.2 & 4.9 \\
\hline Unigene22850_All & $S A M D C$ & Polyamines & 11.6 & -10.6 \\
\hline Unigene16582_All & $P A O$ & Polyamines & 2.6 & 1 \\
\hline CL2187.Contig18_All & $A U X 1$ & AUXIN signal & -10.6 & -4.7 \\
\hline CL5808.Contig3_All & $A U X / I A A$ & AUXIN signal & -13 & 1.2 \\
\hline Unigene18856_All & $A R F$ & AUXIN signal & -12.3 & 11.3 \\
\hline CL4407.Contig1_All & TRIT1 & Cytokinin synthesis & 2.1 & -1.5 \\
\hline Unigene2420_All & CRE1 & Cytokinin signal & 14.0 & 2.9 \\
\hline Unigene17496_All & $B-A R R$ & Cytokinin signal & 15.4 & 14.7 \\
\hline Unigene11345_All & $A-A R R$ & Cytokinin signal & 10.6 & 11.4 \\
\hline Unigene19592_All & $D E L L A$ & Gibberellin signal & 12.9 & -1.4 \\
\hline Unigene27460_All & GA3/CYP701 & Gibberellin synthesis & -2.0 & 3.9 \\
\hline CL7589.Contig3_All & $A B A 2$ & ABA synthesis & 11.3 & 2.1 \\
\hline CL5280.Contig2_All & $P Y R / P Y L$ & ABA signal & 6.6 & -4.7 \\
\hline Unigene217_All & EIN2 & Ethylene signal & -1.3 & -1 \\
\hline Unigene2682_All & $E B F 1 / 2$ & Ethylene signal & -5.6 & -5 \\
\hline Unigene38355_All & CTH & Ethylene synthesis & -11.9 & - \\
\hline Unigene6360_All & $J A R 1$ & Jasmonic acid signal & 1.8 & 1.2 \\
\hline Unigene28086_All & $J A Z$ & Jasmonic acid signal & 5.7 & -4.6 \\
\hline Unigene32397_All & NPR1 & Salicylic acid signal & -13.1 & -2.3 \\
\hline CL3069.Contig6_All & $T G A$ & Salicylic acid signal & -6.1 & -5 \\
\hline CL11268.Contig2_All & ND1 & Oxidative phosphorylation & 3 & 1 \\
\hline CL4559.Contig2_All & ND6 & Oxidative phosphorylation & 8.2 & -3.7 \\
\hline CL3850.Contig1_All & $\mathrm{COX} 3$ & Oxidative phosphorylation & 14.4 & -12.9 \\
\hline CL5613.Contig1_All & $A C O X$ & Stress-response & 1.8 & 2.7 \\
\hline CL2833.Contig1_All & $C A T$ & Stress-response & 3.5 & -2.9 \\
\hline CL5637.Contig1_All & $A P X$ & Stress-response & 5.1 & 4.3 \\
\hline CL8467.Contig1_All & $S O D$ & Stress-response & 1.8 & -1.1 \\
\hline CL7474.Contig1_All & $C D P K$ & Stress-response & 2.9 & -3.2 \\
\hline CL10919.Contig1_All & HSP90 & Stress-response & 6.8 & -1.3 \\
\hline Unigene15666_All & $S G T 1$ & Stress-response & 2.2 & 2.3 \\
\hline CL3327.Contig4_All & $\mathrm{FabH}$ & Fatty acid biosynthesis & 2.7 & -1.9 \\
\hline Unigene24187_All & $a c c C$ & Fatty acid biosynthesis & 4.8 & 4.5 \\
\hline Unigene8973_All & FatB & Fatty acid biosynthesis & 3.1 & -2.5 \\
\hline Unigene26934_All & $F a b D$ & Fatty acid biosynthesis & 3.8 & 2.6 \\
\hline Unigene9530_All & SERK & Transcription factor & 1.8 & 2.4 \\
\hline CL11093.Contig1_All & $L E C 1$ & Transcription factor & 1.7 & 3.1 \\
\hline Unigene10107_All & $W U S$ & Transcription factor & 4.1 & 4.1 \\
\hline Unigene26347_All & $B B M$ & Transcription factor & 2.9 & 1.8 \\
\hline CL5242.Contig1_All & $A G L 15$ & Transcription factor & 1.2 & 1.1 \\
\hline CL7829.Contig6_All & $C K I$ & Transcription factor & 2.8 & -1.9 \\
\hline
\end{tabular}

For homologous genes, the unigene with the highest absolute value of the fold change was selected. The positive and negative number represent up- and down-regulation, respectively. - Indicates unchanged 
NEC. From EC to SEs, the expression level of $A U X 1$ was further decreased whereas the expression level of $A R F$ was increased (Table 2; Supplementary Fig. 2). TRIT1, a gene related to cytokinin (zeatin) biosynthesis, was up-regulated in EC but down-regulated in SEs. CRE1 involved in cytokinin signal transduction was up-regulated in EC and remained high in SEs (Fig. 3; Table 2; Supplementary Fig. 2). Another two genes involved in cytokinin signal transduction, $A-A R R$ and $B-A R R$, showed a similar expression pattern as $C R E 1$, although compared to EC, SEs had a decreased level of $A$-ARR (Supplementary Fig. 2).

To monitor changes of auxin and cytokinin during SE, we measured the concentrations of endogenous IAA and KT in NEC, EC and SEs by ELLISA assay. The IAA concentration was the highest in NEC and decreased in EC and then slightly increased in SEs. The concentration of KT increased in EC and then significantly decreased in SEs. These results were consistent with the expression levels of AAO1-2, CYP71A13 and TRIT1 in these samples (Figs. 3, 4a). SE can be controlled using different combinations of 2,4-D and KT, or IBA and KT (Fig. 3). With the reduction of 2,4-D concentration in the media, the callus became loose and granular in texture and yellow-green in color, a sign for efficient EC induction. The combination of IBA and KT significantly increased the fresh weight and the number of total embryos (Fig. 4b, c). Together, these results confirmed that auxin and cytokinin are critical regulators during cotton SE and that the role of IBA and KT in transition from NEC to SEs was supported by their dynamic changes of expression levels during the transition.

\section{Polyamines promoted cotton SE}

Based on KEGG analysis and GO annotation, the genes involved in polyamine synthesis or metabolism, including $S A M D C, A D C, S P D S, S P M S$ and $P A O$, were found to be differentially expressed during cotton SE. All of these genes, particularly $S A M D C$ and $P A O$, showed a higher expression level in EC compared with NEC. The expression levels of $S A M D C, A D C$ and $S P D S$ were decreased in SEs compared with EC, but the expression level of SPMS was further increased in SEs while that of $P A O$ remained unchanged in SEs (Fig. 3; Table 2 and Supplementary Fig. 2).

We measured the concentrations of the three common PAs (Put, Spd and Spm) in NEC, EC and SEs. The concentrations of Spd and total PA showed significant increase in EC and SEs compared to NEC. Although the levels of all three types of PAs and the total PAs did not show significant difference between NEC and EC, the levels of Spd as well as the total PAs were significantly increased in SEs whereas the levels of Put and Spm largely remained unchanged in SEs (Fig. 4d). Nevertheless, application of exogenous Put in the medium significantly increased the growth of EC and the number of SEs (Fig. 4e, f). These results demonstrated that polyamines played a critical role in promoting the conversion of EC to SEs, Put and Spd might function similarly and are mutually substitutable.

\section{Cotton $\mathrm{SE}$ is regulated by reactive oxygen species (ROS)}

According to our transcriptomic data, some oxidative phosphorylation related genes, including NADH dehydrogenase, succinate dehydrogenase, cytochrome $\mathrm{C}$ oxidase and $\mathrm{A} / \mathrm{F} / \mathrm{V}$ type ATPase, were differentially expressed amongst NEC, EC and SEs (Fig. 3; Table 2). The NADH dehydrogenase related genes, such as the $N D, N d u f s$ and $N d h$ family genes were up-regulated in EC and SEs compared to NEC. The genes in succinate dehydrogenase pathway, such as $S D H C$, $S D H A$ and $S D H B$ were also differentially expressed during cotton $\mathrm{SE}$. The cytochrome $\mathrm{C}$ oxidase encoding genes, including $C O X s$, ISP, Cyt1/b, COR1 and QCRs showed an up-regulated pattern in EC and SEs. The ATPase (includes A, F and V-type) genes, such as beta, alpha, delta and OSCP had a relatively high expression level in EC (Fig. 3; Table 2 and Supplementary Fig. 2). Differential expression of genes related to oxidative phosphorylation indicated that energy metabolism is very active in the transition from NEC to EC and development of SEs.

Additionally, genes encoding the protective system enzymes, including CAT, SOD, POD and APX were upregulated in EC and SEs (Fig. 3; Table 2 and Supplementary Fig. 2). These genes are involved in the antioxidant system and might play a role in maintaining ROS homeostasis during the differential and development of EC and SEs. The concentration of endogenous $\mathrm{H}_{2} \mathrm{O}_{2}$ was slightly higher in EC and SEs than in NEC as revealed by DAB staining (Fig. 4). Applying $1 \mathrm{mM} \mathrm{H}_{2} \mathrm{O}_{2}$ in the medium significantly increased the number of SEs (Fig. $4 \mathrm{j}, \mathrm{k}$ ), suggesting that ROS played a crucial role in the development of EC and SEs during cotton SE.

\section{Stress induced cotton $\mathrm{SE}$}

We found that many stress response related genes, such as $C D P K, H S P 90, S G T$ and genes encoding the protective system enzymes like NOX, SOD, CAT, POD, APX, SAMDC, PAO were differentially expressed during cotton SE (Fig. 3; Table 2). To know the role of stresses in differential and development of SEs, the effects of different concentrations of $\mathrm{NaCl}(0-100 \mathrm{mM})$ and simulated drought stress on cotton SE were investigated by adding Phytagel ( $4 \mathrm{~g} / \mathrm{L})$ into the MS medium. After 4-week of $\mathrm{NaCl}$ treatment, EC growth was promoted by relatively lower concentrations of $\mathrm{NaCl}$ $(\leq 50 \mathrm{mM})$ but inhibited by the high concentration of $\mathrm{NaCl}$ (100 mM). Compared to the control, the 25 and the $50 \mathrm{mM}$ 
(A)

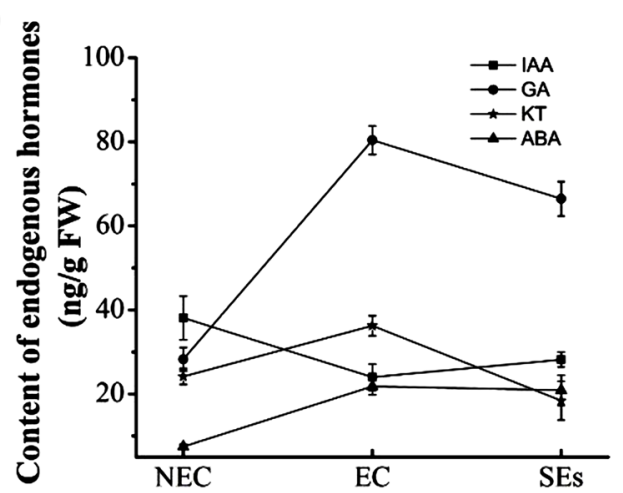

(D)

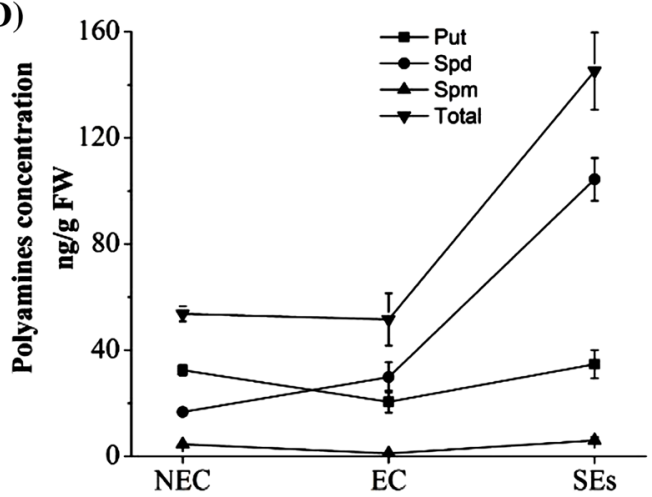

(G)

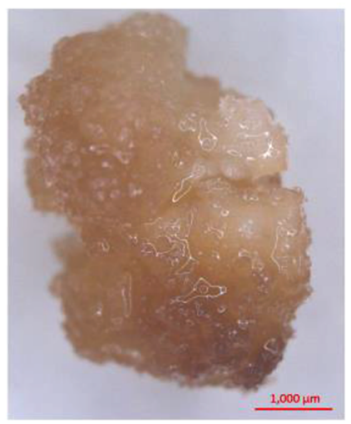

(J)

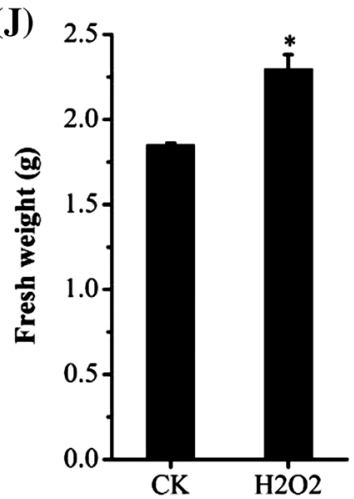

(B)

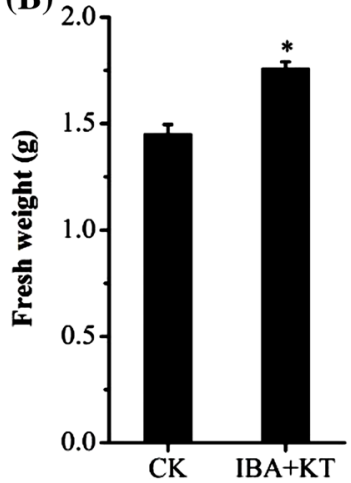

(E)

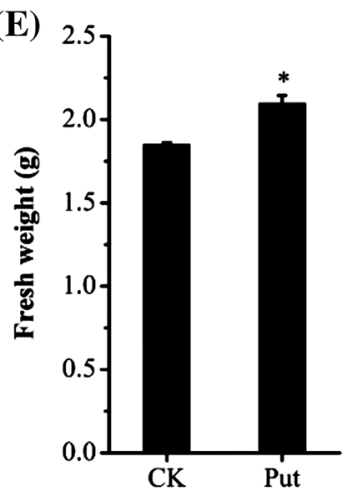

(H)

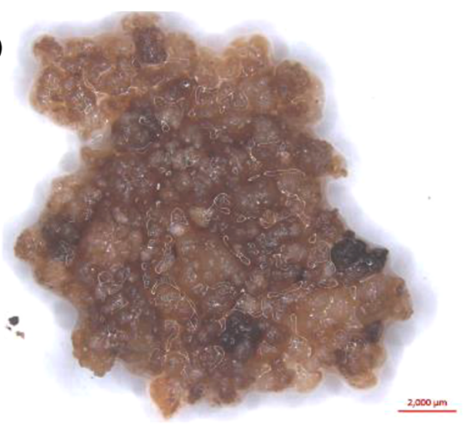

(K)

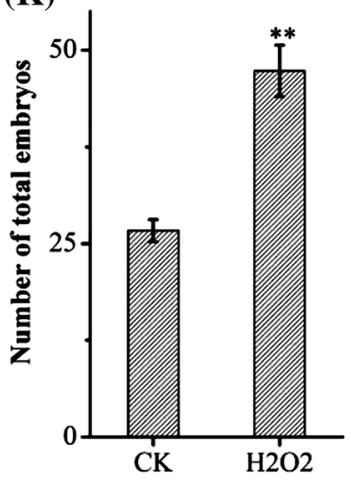

(C)

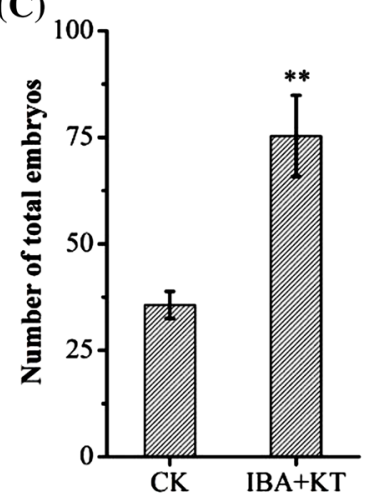

(F)

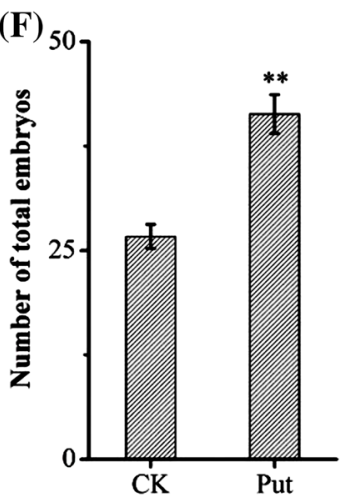

(I)

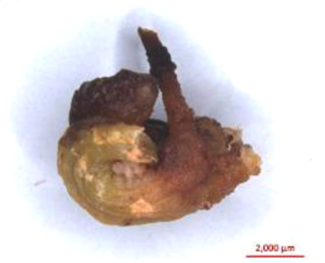

Fig. 4 Comparison of endogenous IAA, KT, GA, ABA, polyamines and $\mathrm{H}_{2} \mathrm{O}_{2}$ at different stages of SE and their effects on the growth of embryogenic callus and somatic embryos. a Determination of the endogenous level of IAA, KT, GA and ABA with ELLISA assay. b Effect of IBA and KT on the growth of somatic embryogenic callus. c Effect of IBA and KT on the number of somatic embryos. d Determination of polyamines using the HPLC assay. e Effect of put on the growth of somatic embryogenic callus. f Effect of put on the number of somatic embryos. $g$ DAB staining of $\mathrm{H}_{2} \mathrm{O}_{2}$ in non-embryogenic callus. h DAB staining of $\mathrm{H}_{2} \mathrm{O}_{2}$ in embryogenic callus. i DAB staining of $\mathrm{H}_{2} \mathrm{O}_{2}$ in somatic embryo. $\mathbf{j}$ Effect of $\mathrm{H}_{2} \mathrm{O}_{2}$ on the growth of somatic embryogenic callus. k Effect of $\mathrm{H}_{2} \mathrm{O}_{2}$ on the number of somatic embryos. * and $* *$ indicate significant differences compared with the control (CK) at $\mathrm{P}<0.05$ and $\mathrm{P}<0.01$, respectively, according to the LSD multiple range test 
treatments slightly and significantly increased the fresh weight of EC, respectively, but the $100 \mathrm{mM}$ treatment had very significant adverse effect on EC growth (Supplementary Fig. 3), and no EC finally survived in the MS medium containing $100 \mathrm{mM}$ of $\mathrm{NaCl}$. Consequently, after 4-weeks of culture, significantly more SEs were observed in the medium containing $50 \mathrm{mM}$ of $\mathrm{NaCl}$ than in the control medium (Fig. 3). Similarly, in the drought stress treatment, more SEs in the medium with $4 \mathrm{~g} / \mathrm{L}$ Phytagel were observed than in the control medium $(2.5 \mathrm{~g} / \mathrm{L})$ after 4-weeks of culture (Fig. 3 and Supplementary Fig. 4). These results suggest that low and moderate stresses were beneficial for EC proliferation and differential of SEs.

\section{Fatty acid biosynthesis and metabolism during cotton SE}

Fatty acids, as a type of protective chemical in reproduction and seed preservation, play a very significant role in the evolution and developmental processes. Fatty acids in plants, as in all other organisms, are the major structural components of membrane phospholipids and triacylglycerol storage oils. During cotton SE, genes related to fatty acid biosynthesis, including $F a b D, F a b H$, accC and $F a t B$, were up-regulated in EC compared to NEC, but down-regulated in SEs compared to EC (Table 2 and Supplementary Fig. 2). The genes involved in metabolism of fatty acids, such as $A C O X 1, A C O X 3, f a d A, f a d B$ and $f a d I$ showed an expression pattern opposite to those in EC and SEs. These results indicated that fatty acids accumulated during the development of EC, a situation similar to initialization of plant seeds.

\section{Discussion}

\section{Transcription factors regulate SE}

During the past three decades, numerous transcription factors and protein kinases, and a wide range of hormones have been shown to play a role in SE in different plant species (El Ouakfaoui et al. 2010; Mahdavi-Darvari et al. 2015). The SERK family genes, LEC, WUS and genes encoding germin-like proteins were implicated in the signal transduction pathway and transcriptional regulation during SE (aan den Toorn et al. 2015; Gaj et al. 2005; Podio et al. 2014; Zuo et al. 2002). $L E C 1, L E C 2$ and FUS3 are key genes that control SE process (Fambrini et al. 2006; Gaj et al. 2005). The capacity of SE is completely repressed in double (lec1 lec2, lec1 fus3, lec2 fus3) or triple (lec1 lec2 fus3) mutants in Arabidopsis thaliana (Gaj et al. 2005). The expression level of $L E C 2 / F U S$ changes rapidly in response to auxin treatment (Stone et al. 2008), suggesting that LEC/FUS may be the upstream genes in the auxin signaling pathway (Gaj et al.
2005; Stone et al. 2001). $B B M$ was similar to the $A P 2 / E R F$ family genes and expressed preferentially in developing embryos (Boutilier et al. 2002). Over-expression of AGL15 enhanced production of secondary embryos from cultured zygotic embryos in A. thaliana (Harding et al. 2003). In our study, these referenced TF genes were found to be differentially expressed during cotton SE (Fig. 3; Table 2).

We found that 302 and 112 TFs were differentially expressed during the transition from NEC to EC and the development of SEs, respectively. According to Yang et al. (2012), of the total 466 differentially expressed TFs during cotton SE, 338 were found during the transition from NEC to EC and 342 were found during development of SEs. More differentially expressed TFs identified by Yang et al. (2012) during development of SEs could be due to the difference in the samples used. Yang et al. (2012) used globular embryos, torpedo embryos and cotyledon embryos individually, while we used a mixture of three types of embryos, which could have compromised the sensitivity of DEG identification.

\section{Auxin and cytokinin are important regulators for cotton $\mathrm{SE}$}

Auxin and cytokinin are critical plant growth regulators (PGRs) for the induction of SE. Their regulatory role is probably achieved by establishing auxin and cytokinin gradients during the induction phase of SE, and is essential for initiating dedifferentiation and cell division of already differentiated cells before they can express embryogenic competence (Sharma et al. 2008; Su et al. 2011). Despite the absolute requirement for exogenous auxin to sustain growth of plant cells cultured in vitro, cultured plant cells produce substantial amounts of the native auxin, IAA. Comprehensive studies have been conducted on callogenesis from several cotton cultivars using various explants, and different combinations of growth regulators. The concentrations of IAA and KT were different in NEC, EC and SEs during cotton SE. Concentration of IAA decreased but concentration of KT increased in the EC stage compared to the NEC stage, consistent with the expression levels of genes involved in IAA and cytokinin biosynthesis (Table 2). This dynamics of auxin and cytokinin played a very important role in the transition from NEC to EC and the development of SEs (Yang et al. 2012; Xu et al. 2013). Previous studies had also shown that sharp changes in endogenous auxin and cytokinin levels might be one of the first steps leading to $\mathrm{SE}$ (Thomas et al. 2002). Our experimental results on the role of exogenously applied IBA and cytokinin on SE (Fig. 3) were consistent with previous studies, i.e. induction of NEC from hypocotyl requires addition of 2,4-D into the medium, but to induce EC and SEs, the concentration of 2,4-D in the medium was decreased to a lower level or replaced by combination of IBA and KT (Kumar et al. 2015; Sun 


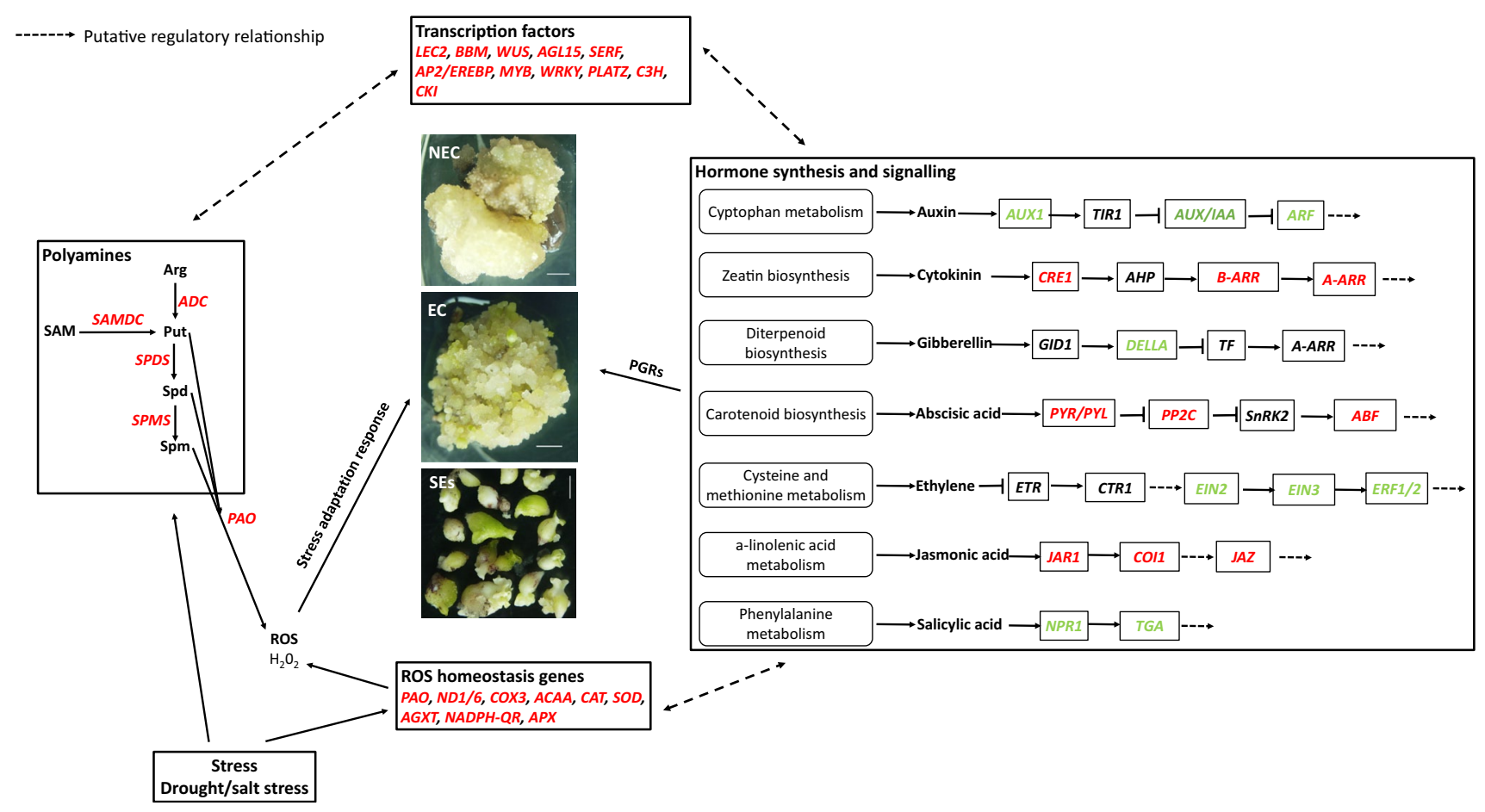

Fig. 5 A proposed model for a role of TFs, hormones, stresses, polyamines and ROS in cotton somatic embryogenesis. Italic words represent genes with down- and up-regulated genes highlighted in green and red color, respectively

et al. 2006). However, the role of auxin and cytokinin is not achieved alone, but by interacting with other pathways and components involved in differential and development of SEs, such as their upstream TF regulators, hormone signaling pathways and ROS. Further studies are required to understand the interactive relationship of these components involved in the complex network regulating cotton SE.

\section{Relationship between polyamines and SE}

Polyamines have been previously linked to plant stress response and SE (Yoda et al. 2009). Many studies have demonstrated the importance of PAs for SE in several plant species (De-la-Peña et al. 2015; Feirer et al. 1984), probably by promoting cellular differentiation during SE (Gemperlová et al. 2009; Montague et al. 1978, 1979; Niemenak et al. 2012). The concentrations of polyamines increased during the early stages of SE in conifers but decreased during the late stages (Gemperlová et al. 2009; Paul et al. 2009). Application of putrescine, spermidine and spermine significantly improved SE in Theobroma cacao L, Citrus sinensis and Hurst Ecotype (Malá et al. 2012; Silva et al. 2009; Wu et al. 2009). In our study, the levels of Spd significantly increased in SEs and the levels of Put and Spm almost did not change, a result reflected by the expression levels of the genes, such as $S A M D C, A D C$ and $S P D S$, encoding enzymes catalyzing the production of PAs (Table 2; Fig. 3 and Supplementary Fig. 2). Both our transcriptomic and qRT-PCR data showed that the key genes for biosynthesis of PAs were expressed at a higher level in EC (e.g. $A D C$ and $S A M D C$ ), or in both EC and SEs (e.g. SPDS and SPMS; Table 2; Fig. 3). Both ADC mRNA and protein were localized in dividing cells of embryo meristems, probably required for mitosis (Vuosku et al. 2006). Exogenous application of Put and Spm enhanced the growth of embryogenic cultures of Araucaria angustifolia and significantly affected the endogenous concentrations of PAs, IAA and ABA in embryogenic tissues (Steiner et al. 2007). Our results also showed that exogenous application of Put enhanced the growth and the development of cotton SEs (Fig. 3), which could be achieved by PAs-mediated regulation of specific physiological processes important for cellular differentiation.

\section{Possible roles of other hormones in cotton SE}

In addition to auxin and cytokinin, genes related to biosynthesis and signaling of other hormones, including gibberellin, abscisic acid, ethylene, brassinosteroid, jasmonic acid and salicylic acid, were also differentially expressed in NEC, EC and SEs (Table 2 and Supplementary Fig. 5). The gibberellin synthesis and signal transduction genes, GA3/CYP701 and $K A O$, were down-regulated in EC but upregulated in SEs. Endogenous GA was at higher levels in EC and SEs than NEC (Fig. 4a). DELLA, a negative regulatory factor (Ueguchi-Tanaka et al. 2008), was up-regulated in EC and down-regulated in SEs. ABA synthesis and signal 
transduction related genes were up-regulated in EC and SEs, including $A B A 2, N C E D, P P 2 C, A B F$ and $P Y R / P Y L$. ABA levels increased in EC and SEs, which was consistent with the expression levels of the genes for ABA synthesis (Fig. 4a). SE of carrot (Daucus carota L.) and Hevea brasiliensis required $\mathrm{ABA}$ as the source of growth regulator in medium (Dunstan et al. 1988; Etienne et al. 1993). Ethylene and polyamines shared the common precursor SAM, always played a competitive role in SE (Bai et al. 2013; Linkies and Leubner-Metzger 2012). Genes related to ethylene synthesis and signal transduction, CTH, cysK, GOT1, EIN2 and EIN3, were down-regulated in EC and SEs compared with NEC, and our data showed a competitive role between PAs and ethylene in cotton SE. JA synthesis and signal transduction related genes, such as $J A R 1, C O I-1$ and $J A Z$ were up-regulated in SEs, but these genes were down-regulated in EC. SA related genes had an opposite expression pattern with JA in such process. Genes of CYP90C1/ROT3, CYP85A1/BR6OX1 and CYP734A1/BAS1, involved in BRs synthesis and signaling, were down-regulated in EC but upregulated in SEs. These hormones may play different roles in cotton SE, and the exact regulatory mechanisms will be discussed in our future work.

In conclusion, the transcriptome analysis unveiled the complex and dynamic nature of the gene network involved in cell dedifferentiation and redifferentiation during cotton SE, and identified the key regulators important for cotton SE. Our results further confirmed the main findings previously reported for cotton SE, mainly revealed the importance of genes involved in the polyamine metabolic pathways and stress response in cotton SE. Based on our results and previous reports, we proposed a working model for the potential gene network essential for successful SE (Fig. 5). In this model, we propose that TFs are the top layer players regulating reprogramming of the transcriptome required for cell dedifferentiation and redifferentiation, and that the hormone synthesis and signaling pathways, stress-response pathways and PA metabolic pathways function side-by-side and synergistically to promote embryogenic cell initiation and plantlet regeneration.

Acknowledgments We thank Dr William J. Gale (College of Agriculture, Shihezi University, China) for critical reading and professional editing of the manuscript. This work was supported by the National Key Research Projects of China (Grant No. 2016YFD0100203), National Natural Science Foundation of China (Grant No. 31301363), Special Program of Xinjiang Production and Construction Croups: Germplasm Functional Gene Discovery (Grant No. 2012BB049) and Xinjiang Production and Construction Groups programs for Science and Technology development (2014BA004).

Author contributions Conceived and designed the experiments: Wen-Han Cheng, Hua-Guo Zhu and Jie Sun. Performed the experiments: Wen-Han Cheng, Wen-Gang Tian, Xian-Peng Xiong and Shou-Hong Zhu. Analyzed the data: Wen-Han Cheng, Hua-Guo Zhu.
Contributed reagents/materials/analysis tools: Jie Sun, Yu-Qiang Sun. Wrote the paper: Wen-Han Cheng, Yu-Qiang Sun and Qian-Hao Zhu.

\section{Compliance with ethical standards}

Conflict of interest The authors declare that the research was conducted in the absence of any commercial or financial relationships that could be construed as a potential conflict of interest.

Open Access This article is distributed under the terms of the Creative Commons Attribution 4.0 International License (http://creativecommons.org/licenses/by/4.0/), which permits unrestricted use, distribution, and reproduction in any medium, provided you give appropriate credit to the original author(s) and the source, provide a link to the Creative Commons license, and indicate if changes were made.

\section{References}

aan den Toorn M, Albrecht C, de Vries S (2015) On the origin of SERKs: bioinformatics analysis of the somatic embryogenesis receptor kinases. Mol Plant 8:762-782

Bai B, Su YH, Yuan J, Zhang XS (2013) Induction of somatic embryos in Arabidopsis requires local YUCCA expression mediated by the down-regulation of ethylene biosynthesis. Mol Plant 6:1247-1260

Boutilier K et al (2002) Ectopic expression of BABY BOOM triggers a conversion from vegetative to embryonic growth. Plant Cell 14:1737-1749

Chen R, Cheng W, Cui J, Liao J, Fan H, Zheng Z, Ma F (2015) Lateral spacing in drip-irrigated wheat: the effects on soil moisture, yield, and water use efficiency. Field Crops Res 179:52-62

Cheng W-H, Wang F-L, Cheng X-Q, Zhu Q-H, Sun Y-Q, Zhu H-G, Sun $\mathrm{J}$ (2015) Polyamine and its metabolite $\mathrm{H}_{2} \mathrm{O}_{2}$ play a key role in the conversion of embryogenic callus into somatic embryos in upland cotton (Gossypium hirsutum L.). Front Plant Sci. doi: $10.3389 /$ fpls.2015.01063

De-la-Peña C, Nic-Can GI, Galaz-Ávalos RM, Avilez-Montalvo R, Loyola-Vargas VM (2015) The role of chromatin modifications in somatic embryogenesis in plants. Front Plant Sci 6:635

Dunstan DI, Bekkaoui F, Pilon M, Fowke LC, Abram SR (1988) Effects of abscisic acid and analogues on the maturation of white spruce (Picea glauca) somatic embryos. Plant Sci 58:77-84

El Ouakfaoui S et al. (2010) Control of somatic embryogenesis and embryo development by AP2 transcription factors. Plant Mol Biol 74:313-326

Etienne H, Sotta B, Montoro P, Miginiac E, Carron M-P (1993) Relations between exogenous growth regulators and endogenous indole-3-acetic acid and abscisic acid in the expression of somatic embryogenesis in Hevea brasiliensis (Müll. Arg.) Plant Sci 88:91-96

Fambrini M et al (2006) Characterization of LEAFY COTYLEDON1LIKE gene in Helianthus annuus and its relationship with zygotic and somatic embryogenesis. Dev Genes Evol 216:253-264

Feirer RP, Mignon G, Litvay JD (1984) Arginine decarboxylase and polyamines required for embryogenesis in the wild carrot. Science 223:1433-1435

Gaj MD, Zhang S, Harada JJ, Lemaux PG (2005) Leafy cotyledon genes are essential for induction of somatic embryogenesis of Arabidopsis. Planta 222:977-988

Gemperlová L, Fischerová L, Cvikrová M, Malá J, Vondráková Z, Martincová O, Vágner M (2009) Polyamine profiles and biosynthesis in somatic embryo development and comparison of germinating somatic and zygotic embryos of Norway spruce. Tree Physiol 29:1287-1298 
Harding EW, Tang W, Nichols KW, Fernandez DE, Perry SE (2003) Expression and maintenance of embryogenic potential is enhanced through constitutive expression of AGAMOUS-Like 15. Plant Physiol 133:653-663

Hecht V, Vielle-Calzada J-P, Hartog MV, Schmidt ED, Boutilier K, Grossniklaus U, de Vries SC (2001) The Arabidopsis SOMATIC EMBRYOGENESIS RECEPTOR KINASE 1 gene is expressed in developing ovules and embryos and enhances embryogenic competence in culture. Plant Physiol 127:803-816

Kaul S et al (2000) Analysis of the genome sequence of the flowering plant Arabidopsis thaliana. Nature 408:796-815

Kumar GP et al (2015) Evaluation of different carbon sources for high frequency callus culture with reduced phenolic secretion in cotton (Gossypium hirsutum L.) cv. SVPR-2. Biotechnol Reports 7:72-80

Li F et al (2015) Genome sequence of cultivated Upland cotton (Gossypium hirsutum $\mathrm{TM}-1$ ) provides insights into genome evolution. Nat Biotechnol 33:524-530

Linkies A, Leubner-Metzger G (2012) Beyond gibberellins and abscisic acid: how ethylene and jasmonates control seed germination. Plant Cell Reports 31:253-270

Lotan $\mathrm{T}$ et al (1998) Arabidopsis LEAFY COTYLEDON1 is sufficient to induce embryo development in vegetative cells. Cell 93:1195-1205

Mahdavi-Darvari F, Noor NM, Ismanizan I (2015) Epigenetic regulation and gene markers as signals of early somatic embryogenesis Plant Cell Tiss Organ Cult (PCTOC) 120:407-422

Malá J, Gemperlová L, Cvikrová M, Máchová P (2012) Role of polyamines in efficiency of Norway spruce (hurst ecotype) somatic embryogenesis. INTECH open access publisher

Mantiri FR et al (2008) The transcription factor MtSERF1 of the ERF subfamily identified by transcriptional profiling is required for somatic embryogenesis induced by auxin plus cytokinin in Medicago truncatula. Plant Physiol 146:1622-1636

Markram H, Lübke J, Frotscher M, Sakmann B (1997) Regulation of synaptic efficacy by coincidence of postsynaptic APs and EPSPs. Science 275:213-215

Mayer K et al (1999) Sequence and analysis of chromosome 4 of the plant Arabidopsis thaliana. Nature 402:769-777

Min L et al (2015) LEAFY COTYLEDON1-CASEIN KINASE I-TCP15-PHYTOCHROME INTERACTING FACTOR4 network regulates somatic embryogenesis by regulating auxin homeostasis. Plant Physiol 169:2805-2821

Montague MJ, Koppenbrink JW, Jaworski EG (1978) Polyamine metabolism in embryogenic cells of Daucus carota I. Changes in intracellular content and rates of synthesis. Plant Physiol 62:430-433

Montague MJ, Armstrong TA, Jaworski EG (1979) Polyamine metabolism in embryogenic cells of Daucus carota II. Changes in arginine decarboxylase activity. Plant Physiol 63:341-345

Niemenak N, Awah TM, Lieberei R (2012) Establishment of suspension culture in Theobroma cacao and polyamines associated with cacao embryogenesis. Plant Growth Regul 67:1-8

Paul A, Mitter K, Raychaudhuri SS (2009) Effect of polyamines on in vitro somatic embryogenesis in Momordica charantia L. Plant Cell Tiss Organ Cult (PCTOC) 97:303-311

Podio $M$ et al (2014) Characterization and expression analysis of SOMATIC EMBRYOGENESIS RECEPTOR KINASE (SERK) genes in sexual and apomictic Paspalum notatum. Plant Mol Biol 84:479-495

Sharma SK, Millam S, Hedley PE, McNicol J, Bryan GJ (2008) Molecular regulation of somatic embryogenesis in potato: an auxin led perspective. Plant Mol Biol 68:185-201

Silva TE, Cidade LC, Alvim FC, Cascardo JC, Costa MG (2009) Studies on genetic transformation of Theobroma cacao L.: evaluation of different polyamines and antibiotics on somatic embryogenesis and the efficiency of uidA gene transfer by Agrobacterium tumefaciens. Plant Cell Tiss Organ Cult (PCTOC) 99:287-298

Steiner N, Santa-Catarina C, Silveira V, Floh EI, Guerra MP (2007) Polyamine effects on growth and endogenous hormones levels in Araucaria angustifolia embryogenic cultures. Plant Cell Tiss Organ Cult 89:55-62

Stone SL et al (2001) LEAFY COTYLEDON2 encodes a B3 domain transcription factor that induces embryo development. Proc Nat Acad Sci 98:11806-11811

Stone SL et al (2008) Arabidopsis LEAFY COTYLEDON2 induces maturation traits and auxin activity: implications for somatic embryogenesis. Proc Nat Acad Sci 105:3151-3156

Su Y-H, Liu Y-B, Zhang X-S (2011) Auxin-cytokinin interaction regulates meristem development. Molecular Plant 4:616-625

Sun Y, Zhang X, Huang C, Guo X, Nie Y (2006) Somatic embryogenesis and plant regeneration from different wild diploid cotton (Gossypium) species. Plant Cell Reports 25:289-296

Thomas C, Bronner R, Molinier J, Prinsen E, van Onckelen H, Hahne G (2002) Immuno-cytochemical localization of indole-3-acetic acid during induction of somatic embryogenesis in cultured sunflower embryos. Planta 215:577-583

Ueguchi-Tanaka M, Hirano K, Hasegawa Y, Kitano H, Matsuoka M (2008) Release of the repressive activity of rice DELLA Protein SLR1 by gibberellin does not require SLR1 degradation in the gid2 mutant. Plant Cell 20:2437-2446. doi:10.1105/ tpc. 108.061648

Vuosku J et al (2006) Consistency of polyamine profiles and expression of arginine decarboxylase in mitosis during zygotic embryogenesis of Scots pine. Plant Physiol 142:1027-1038

Wang K et al (2012) The draft genome of a diploid cotton Gossypium raimondii. Nat Genet 44:1098-1103

Wu K-M, Lu Y-H, Feng H-Q, Jiang Y-Y, Zhao J-Z (2008) Suppression of cotton bollworm in multiple crops in China in areas with Bt toxin-containing cotton. Science 321:1676-1678

Wu X-B, Wang J, Liu J-H, Deng X-X (2009) Involvement of polyamine biosynthesis in somatic embryogenesis of Valencia sweet orange (Citrus sinensis) induced by glycerol. J Plant Physiol 166:52-62

Xiang L-x, He D, Dong W-r, Zhang Y-w, Shao J-z (2010) Deep sequencing-based transcriptome profiling analysis of bacteria-challenged Lateolabrax japonicus reveals insight into the immune-relevant genes in marine fish. BMC Genomics 11:1

$\mathrm{Xu} \mathrm{Z}$ et al (2013) Transcriptome profiling reveals auxin and cytokinin regulating somatic embryogenesis in different sister lines of cotton cultivar CCRI24. J Integr Plant Biol 55:631-642

Yang X, Zhang X, Yuan D, Jin F, Zhang Y, Xu J (2012) Transcript profiling reveals complex auxin signalling pathway and transcription regulation involved in dedifferentiation and redifferentiation during somatic embryogenesis in cotton. BMC Plant Biol 12:110

Yoda H, Fujimura K, Takahashi H, Munemura I, Uchimiya H, Sano H (2009) Polyamines as a common source of hydrogen peroxide in host-and nonhost hypersensitive response during pathogen infection. Plant Mol Biol 70:103-112

Zeng F, Zhang X, Zhu L, Tu L, Guo X, Nie Y (2006) Isolation and characterization of genes associated to cotton somatic embryogenesis by suppression subtractive hybridization and macroarray*. Plant Mol Biol 60:167-183

Zhang T et al (2015) Sequencing of allotetraploid cotton (Gossypium hirsutum L. acc. TM-1) provides a resource for fiber improvement. Nat Biotechnol 33:531-537

Zuo J, Niu QW, Frugis G, Chua NH (2002) The WUSCHEL gene promotes vegetative-to-embryonic transition in Arabidopsis. Plant J 30:349-359 